Michał Siedlecki*

Dział Naukowy Książnicy Podlaskiej im. Łukasza Górnickiego w Białymstoku https://orcid.org/0000-0002-7575-6799

\title{
„Topos” w Białymstoku. Sprawozdanie
}

Jedną z naukowo-literackich stolic Polski drugiej połowy 2018 roku okazał się miedzy innymi Białystok. Mogliśmy tam bowiem w listopadzie uczestniczyć aż w trzech niezmiernie ważnych wydarzeniach kulturalnych: „Środzie Literackiej” z poetami „Toposu” (14 listopada); uroczystości wręczenia Ogólnopolskiej Nagrody Literackiej im. Franciszka Karpińskiego redaktorowi Krzysztofowi Kuczkowskiemu (15 listopada) oraz Jubileuszowej Konferencji Naukowej „«Topos»: pismo literackie, idea, środowisko artystyczne. W XXV rocznicę wydania pierwszego numeru «Toposu» 1993-2018” (15-16 listopada). Wszystkie spotkania odbyły się w Książnicy Podlaskiej im. Łukasza Górnickiego w Białymstoku.

\section{"Topos"}

„Topos” to dwumiesięcznik literacki ukazujący się od maja 1993 roku. Wydaje go „Towarzystwo Przyjaciół Sopotu”. Został założony przez Krzysztofa Kuczkowskiego, który do dzisiaj nim kieruje. W skład redakcji pisma wchodzą jeszcze Tadeusz Dąbrowski i Wojciech Kass. Jego radę programową tworzą: Edward Balcerzan, Zbigniew Chojnowski, Krzysztof Dybciak, Wojciech Kudy-

\footnotetext{
* Michał Siedlecki - dr, pracownik Działu Naukowego Książnicy Podlaskiej im. Łukasza Górnickiego w Białymstoku; autor monografii Myśliwski metafizyczny. Rozważania o ,Widnokręgu” $i$,Traktacie o tuskaniu fasoli” (Białystok 2015) oraz szeregu artykułów, w tym: Watki podlaskie w twórczości Jana Kamińskiego: behawiorystyczno-ontologiczne ujęcie świata (na podstawie „Fugi” $i$,,Metafizyki prowincji”) (2012).
} 
ba, Wojciech Ligęza, a także David Malcolm. Z dwumiesięcznikiem współpracują ponadto między innymi: Przemysław Dakowicz, Teresa Ferenc, Wojciech Fułek, Ewa Kuczkowska, Wojciech Gawłowski oraz Adrian Gleń. Jest on dofinansowywany ze środków Ministra Kultury i Dziedzictwa Narodowego, Samorządu Województwa Pomorskiego, jak również Gminy Miasta Sopot.

W 2018 roku obchodziliśmy dwudziestą piątą rocznicę wydania pierwszego numeru „Toposu”. Przyjrzyjmy się więc głównym uroczystościom związanym z tym szczególnym wydarzeniem, których znaczna część odbywała się w Białymstoku.

\section{„Środa Literacka”}

Pierwszym ze znaczących wydarzeń w Książnicy Podlaskiej spod znaku „Toposowego" jubileuszu była „Środa Literacka” z udziałem ośmiu artystów związanych z dwumiesięcznikiem: Krzysztofa Kuczkowskiego (poety, autora szkiców, recenzji muzycznych i literackich, wykładowcy, członka jury konkursów literackich, założyciela i redaktora naczelnego „Toposu”), Adriana Glenia (krytyka literackiego, teoretyka literatury, poety, pracownika Uniwersytetu Opolskiego), Artura Nowaczewskiego (poety i krytyka literackiego, adiunkta na Uniwersytecie Gdańskim), Jarosława Jakubowskiego (poety, prozaika, dramatopisarza, krytyka literackiego, dziennikarza), Wojciech Kassa (poety, eseisty, redaktora „Toposu”, sekretarza „Orfeusza” - Nagrody Poetyckiej im. Konstantego Ildefonsa Gałczyńskiego), Wojciecha Gawłowskiego (poety, publicysty, członka Stowarzyszenia Pisarzy Polskich), Przemysława Dakowicza (poety, eseisty, krytyka literackiego i historyka literatury, wykładowcy na Uniwersytecie Kardynała Stefana Wyszyńskiego w Warszawie) i Wojciecha Kudyby (poety, krytyka, historyka literatury, kierownika Katedry Literatury XX wieku na Wydziale Nauk Humanistycznych Uniwersytetu Kardynała Stefana Wyszyńskiego w Warszawie). Spotkanie z pisarzami odbyło się w wypełnionej do ostatniego miejsca sali audytoryjnej białostockiej biblioteki (mogącej pomieścić około stu osób), które poprowadzili jej pracownicy: Dominik Sołowiej oraz Michał Siedlecki.

Prowadzący zadali gościom szereg pytań, w tym te dotyczące: ich debiutów, zjawiska bohemy „Toposu”, literackiego programu pisma (sformułowanego już w pierwszym numerze z maja 1993 roku) i jego wyjątkowości na tle innych magazynów w Polsce, sytuacji dwumiesięcznika w XXI stuleciu czy aktualnych planów wydawniczych poetów. Białostocka publika dopytywała się między in- 


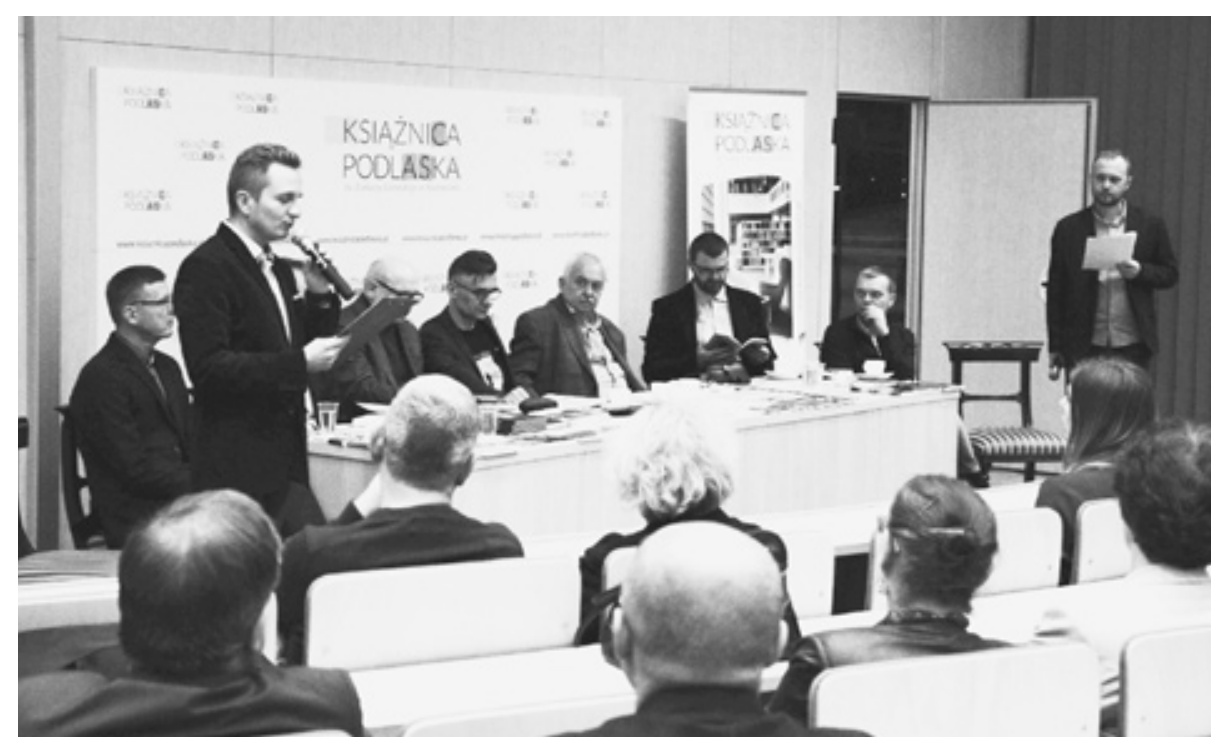

Spotkanie z autorami antologii poezji Konstelacja Toposu (14.11.2018 r.).

Siedzą od lewej: Wojciech Kudyba, Krzysztof Kuczkowski, Wojciech Kass, Wojciech Gawłowski, Przemysław Dakowicz, Adrian Gleń. Prowadzący od lewej (stoją): Dominik Sołowiej (KP, Białystok) oraz Michał Siedlecki (KP, Białystok). Fot. Mona Al-Kaber (KP, Białystok)

nymi szczegółowo pisarzy o: kwestie parytetu w „Toposie”, wzajemne relacje między artystami czy ich kolejne spotkania autorskie. Odpowiedzi poetów były często zróżnicowane, wynikłe w wielu aspektach z ich odmiennej poetyki pisania, lecz nad wyraz zgodne, co do wartości i pryncypiów, po które należy aktualnie sięgać, by nie dać się porwać wzburzonym nurtom płynnej rzeczywistości.

Środowe wydarzenie zakończyło się odczytaniem przez pisarzy liryczno-prozatorskich fragmentów ich twórczości. Po jego oficjalnym zamknięciu przeniosło się ono do kuluarów, gdzie można było jeszcze długo porozmawiać na osobności z artystami czy też nabyć ich książki.

\section{Konferencja}

Dzień później została w Książnicy Podlaskiej (w sali audytoryjnej) zainaugurowana Jubileuszowa Konferencja Naukowa „«Topos»: pismo literackie, idea, środowisko artystyczne. W XXV rocznicę wydania pierwszego numeru «Toposu» 1993-2018”. Gości powitali: prof. Jarosław Ławski (Dziekan Wydzia- 


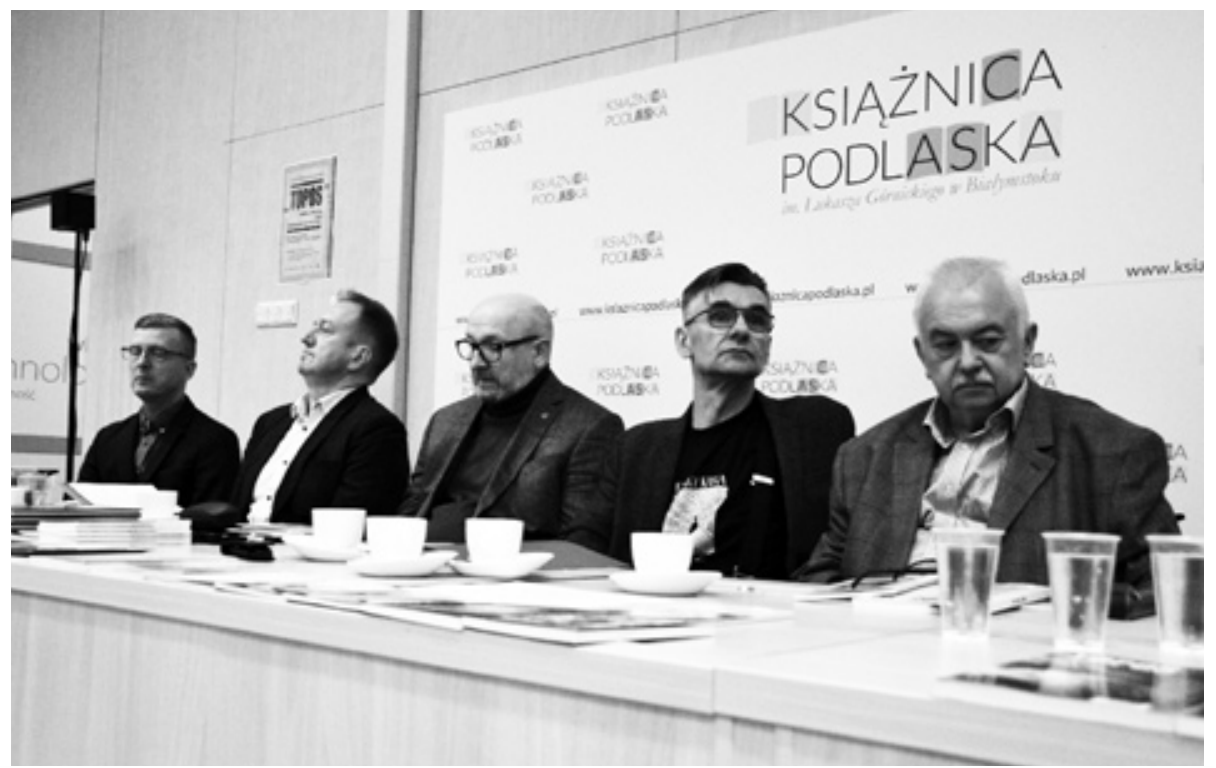

Poeci „Toposu” (14.11.2018 r.). Siedzą od lewej: Wojciech Kudyba, Jarosław Jakubowski, Krzysztof Kuczkowski, Wojciech Kass, Wojciech Gawłowski.

Fot. Mona Al-Kaber (KP, Białystok)

łu Filologicznego UwB); prof. Dariusz Kulesza (kierownik Zakładu Literatury Międzywojennej i Współczesnej UwB) oraz dyr. Jolanta Gadek (Książnica Podlaska im. Łukasza Górnickiego). Sesję otworzył uroczyście red. Krzysztof Kuczkowski (redaktor naczelny „Toposu). Organizatorem imprezy wraz z Książnicą Podlaską i Uniwersytetem w Białymstoku było „Towarzystwo Przyjaciół Sopotu”, wydawca dwumiesięcznika literackiego „Topos”.

Komitet naukowy konferencji współtworzyli: prof. Zbigniew Chojnowski (UWM w Olsztynie); prof. Krzysztof Dybciak (UKSW w Warszawie); dyr. Jolanta Gadek (Książnica Podlaska im. Łukasza Górnickiego); prof. sen. Halina Krukowska (KBF „Wschód - Zachód” UwB); prof. Dariusz Kulesza (Uniwersytet w Białymstoku); prof. Wojciech Ligęza (Uniwersytet Jagielloński w Krakowie); dr hab. Jerzy Sikora, prof. UKSW (UKSW w Warszawie); dr hab. Violetta WejsMilewska, prof. UwB (IFP UwB) oraz prof. Zofia Zarębianka (Uniwersytet Jagielloński w Krakowie).

W skład komitetu organizacyjnego konferencji wchodzili zaś: prof. Jarosław Ławski (KBF „Wschód - Zachód”), dr Krzysztof Korotkich (KBF „Wschód 
- Zachód”), mgr Kamil K. Pilichiewicz (KBF „Wschód - Zachód”), dr Łukasz Zabielski (Książnica Podlaska im. Łukasza Górnickiego), dr Michał Siedlecki (Książnica Podlaska im. Łukasza Górnickiego); dr Małgorzata Burzka-Janik (Uniwersytet Opolski) oraz mgr Joanna Godlewska (Uniwersytet w Białymstoku).

Zagadnienia badawcze sesji oscylowały wokół następujących problemów: „Topos”: historia pisma, recepcja jego dorobku; idea „topoi” w środowisku pisma, jego profil estetyczny i aksjologiczny; konstelacja poetów „Toposu”: indywidualności, idee, tematy, tradycje; „Biblioteka Toposu”: jej twórcy, idee, dzieła, ich interpretacje; poezja i poeci na łamach „Toposu”; debiuty; metafizyczne inklinacje poezji z kręgu „Toposu”; myśl krytycznoliteracka środowiska skupionego wokół pisma; „Topos” i polemiki wokół modelu literatury polskiej w latach 1989/1993-2018; koncepcja słowa w środowisku twórców „Toposu”; życie literackie środowiska: festiwale, nagrody, spotkania autorskie, jak również idee „Toposu” w nowych mediach: radio, Internet, telewizja.

W obradach wzięło udział około trzydziestu badaczy z prestiżowych polskich ośrodków akademickich. Pierwszy dzień sesji został podzielony na trzy części. Swoje wystąpienia wygłosili wpierw następujący prelegenci: prof. Zofia Zarębianka (Uniwersytet Jagielloński, Kraków), Trzy metafizyki poetyckie: Kuczkowski, Kudyba, Kass; prof. dr hab. Krzysztof Krasuski (Uniwersytet Śląski, Katowice), Krytyka literacka pod auspicjami „,Toposu”; dr hab. Artur Grabowski (Uniwersytet Jagielloński, Kraków), Wiersze religijne a poezja wiary. O poetyckich ,wyznaniach” poetów z kręgu „Toposu”; dr hab. Jerzy Sikora, prof. UKSW (Warszawa), „Topos” a inne pisma literackie - podobieństwa i różnice oraz dr Michał Siedlecki (Książnica Podlaska im. Ł. Górnickiego), , Biblioteka Toposu”- zjawisko kulturowe i literackie.

W drugiej części obrad wystąpili zaś tego dnia: prof. Dariusz Kulesza (Uniwersytet w Białymstoku), Nowa poezja chrześcijańska? „Ruchome święta” Krzysztofa Kuczkowskiego; dr Karol Samsel (Uniwersytet Warszawski), Echa transcendentalizmu amerykańskiego w poezji Kazimierza Brakonieckiego; mgr Joanna Godlewska (Uniwersytet w Białymstoku), Mosty kulturowe i metafizyczne. O poezji Wojciecha Gawtowskiego oraz mgr Teresa Radziewicz (Białystok), Światło w poezji Wojciecha Kassa.

W trzeciej części sesji głos zabrali natomiast: mgr Katarzyna Wójcik (Warszawa), Fantomowa religia. O dramacie „Licheń story” Jarosława Jakubowskiego; dr Izabela Rutkowska (PWSZ w Głogowie), Toposy „Toposu”- spoj- 
rzenie z perspektywy retoryki oraz dr Tomasz Pyzik (Katowice), „Wszystko przemienione”. O cyklu wierszy na Wielki Tydzień z tomu „Ruchome święta” Krzysztofa Kuczkowskiego.

Drugi dzień konferencji został zaś podzielony na dwie części, które poprzedził panel: ,,Topos” - pismo i świat idei. Poprowadzili go: prof. Jarosław Ławski oraz prof. Dariusz Kulesza. Tuż po nim swoje referaty wygłosili: Janina Osewska (Augustów), Topos kobiet w „,Toposie”; dr Józef Maria Ruszar (Kraków), Jan Polkowski rozmawia z Tadeuszem Różewiczem; mgr Kamil K. Pilichiewicz (Uniwersytet w Białymstoku), Toposy, konwencje, konstelacje. Wokót sopockiego dwumiesięcznika literackiego; mgr Ireneusz Staroń (Uniwersytet Wrocławski), Rozwiązana i rozwiazła sielanka. Historia i język w „Porwaniu Europy” Krzysztofa Koehlera; prof. dr hab. Zbigniew Chojnowski (UWM w Olsztynie), Kazimierz Nowosielski jako autor ,,Toposu”; dr Karol Alichnowicz (Radom), Wyobraźnia liryczna Wojciecha Kassa; dr hab. Anna Janicka, prof. UwB (Uniwersytet w Białymstoku), Dwie Bułgarie; mgr Paulina Subocz-Białek (Uniwersytet Wrocławski), W pułapce pamięci. Wokót jednego wiersza Jana Polkowskiego z tomu ,Głosy” oraz dr Paweł Wojciechowski (Ateneum - Szkoła Wyższa w Gdańsku), Topos dziecka w ,Toposie”.

Plonem konferencji będzie monografia (recenzowana i punktowana), opublikowana w Naukowym Projekcie Wydawniczym - Serii „Przełomy/Pogranicza”.

\section{Nagroda}

Kluczową imprezą towarzyszącą białostockiej konferencji okazało się wręczenie we czwartek (15 listopada) Ogólnopolskiej Nagrody Literackiej im. Franciszka Karpińskiego redaktorowi Krzysztofowi Kuczkowskiemu. Organizatorami tej podniosłej imprezy były dwie instytucje: Katolickie Stowarzyszenie „Civitas Christiana” (fundator nagrody), jak również Książnica Podlaska im. Łukasza Górnickiego. I to w siedzibie drugiej z nich, w jej przestronnej auli owo wydarzenie miało miejsce.

Kapitułę nagrody tworzą niezmiennie od kilku lat: J. E. ksiądz biskup dr hab. Henryk Ciereszko (przewodniczący kapituły), dyr. Jolanta Gadek, red. Dorota Sokołowska, dyr. Bogusława Wencław, prof. dr hab. Jarosław Ławski, prof. dr hab. Dariusz Kulesza, ks. dr Dariusz Wojtecki, Jan Leończuk oraz Romuald Gumienniak. Jest ona przyznawana przez Katolickie Stowarzyszenie „Civitas Christiana” Oddział Okręgowy w Białymstoku od 1995 roku. Jej 


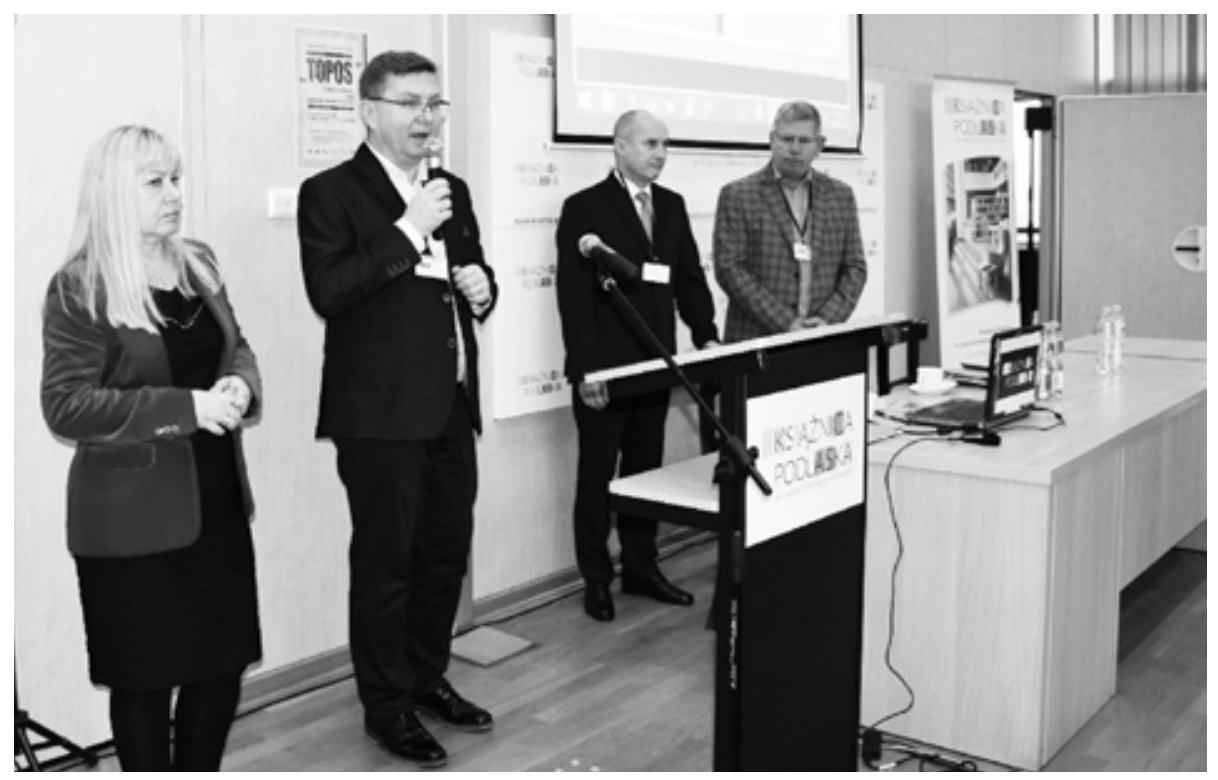

Inauguracja Ogólnopolskiej Jubileuszowej Konferencji Naukowej „«Topos»: pismo literackie, idea, środowisko artystyczne. W XXV rocznicę wydania pierwszego numeru «Toposu» 1993-2018” (15.11.2018 r.). Stoją od lewej: dyr. Jolanta Gadek (KP, Białystok), prof. Jarosław Ławski (Dziekan Wydział Filologicznego, UwB), prof. Dariusz Kulesza (Kierownik Zakładu Literatury Międzywojennej i Współczesnej, UwB) oraz prof. Zbigniew Chojnowski (Kierownik Zakładu Literatury Współczesnej i Teorii Literatury, UWM w Olsztynie).

Fot. Justyna Sawczuk (KP, Białystok)

laureatami zostają wybitne postaci polskiej kultury, których twórczość wyrasta z nurtu chrześcijańskiego.

W poprzednich edycjach uhonorowani zostali nagrodą: ks. Jan Twardowski (1995), prof. dr hab. Irena Sławińska (1996), ks. bp Józef Zawitkowski (1997), Ernest Bryll (1998), ks. prof. dr hab. Janusz Frankowski (1999), Waldemar Smaszcz (2000), Stanisław Szewczenko (2001), Marek Skwarnicki (2002), Jan Leończuk (2003), ks. prof. dr hab. Jan Sochoń (2004), prof. dr hab. Teresa Kostkiewiczowa (2005), prof. dr hab. Anna Świderkówna (2006), prof. dr hab. Halina Krukowska (2007), Ewa Lipska (2008), Edward Redliński (2009), prof. dr hab. Stefan Sawicki (2010), Wojciech Wencel (2011), prof. dr hab. Elżbieta Feliksiak (2012), ks. dr Tadeusz Golecki (2013), dr Przemysław Dakowicz (2014), prof. Wojciech Ligęza (2015), Wiesław Myśliwski (2016) oraz ks. prof. Jerzy Szymik (2017). 


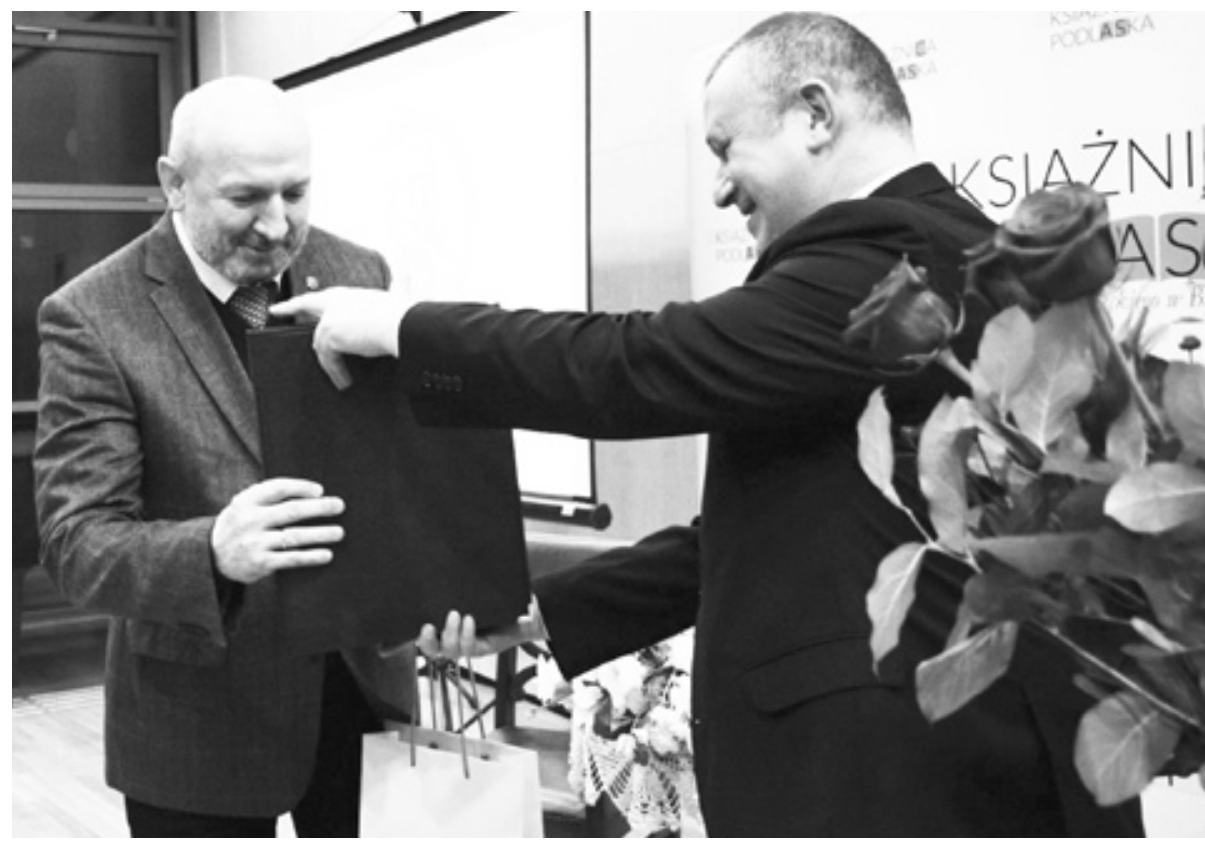

Wręczenie Ogólnopolskiej Nagrody Literackiej im. Franciszka Karpińskiego, przyznawanej przez Katolickie Stowarzyszenie „Civitas Christiana” (15.11.2018 r.).

Od lewej stoją: Krzysztof Kuczkowski (laureat) oraz Romuald Gumieniak (wiceprzewodniczący Katolickiego Stowarzyszenia „Civitas Christiana”). Fot. Bogumiła Maleszewska-Oksztol (KP, Białystok)

Tegoroczny werdykt kapituły Ogólnopolskiej Nagrody Literackiej im. Franciszka Karpińskiego przypomnieli Aneta i Tomasz Filipowicz z Katolickiego Stowarzyszenia „Civitas Christiana” (Oddział Okręgowy w Białymstoku). Redaktor Krzysztof Kuczkowski został bowiem oficjalnie uhonorowany za: „stworzenie oryginalnego modelu poezji metafizycznej oraz zorganizowanie i prowadzenie przez ćwierć wieku dwumiesięcznika «Topos», unikalnego ośrodka kultury i literatury chrześcijańskiej”. Zaprezentowano również film podsumowujący dotychczasowe dokonania literacko-wydawnicze laureata.

Następnie głos zabrał J. E. ksiądz biskup dr hab. Henryk Ciereszko - przewodniczący kapituły, po którym swoją laudację wygłosił prof. dr hab. Dariusz Kulesza. Obaj mówcy nawiązali przede wszystkim do dorobku oraz biogramu twórcy. Przypomnieli o jego roli założyciela oraz redaktora naczelnego dwumiesięcznika literackiego „Topos”, a także redaktora serii książek „Biblioteka 
Toposu". Nadmienili również o licznych zbiorach wierszy artysty, takich choćby jak: Prognoza pogody (1980), Pornografia (1979-1981), Trawa na dachu (wiersze 1989-1991) (1992), Widok z dachu. Wiersze, zapiski, dialogi (1994), Aniot i góra (1996), Niebo w grudniu (1997), Tlen (2003), Dajemy się jak dzieci prowadzić nicości (2007), Wiersze (masowe) i inne (2010), Ruchome święta (2017) czy Sony Liston nie znat liter [siódemki] (2018). Przypomnieli też, że utwory pisarza były tłumaczone na język: angielski, niemiecki, włoski, czeski, serbski i chorwacki. Nawiązali także do jego licznych nagród literackich [m.in. Nagrody „Nowej Okolicy Poetów” za dorobek poetycki (2008), Honorowego Orfeusza (2017) czy Nagrody Literackiej im. Ks. Jana Twardowskiego (2018)] oraz przynależności poety do Stowarzyszenia Pisarzy Polskich.

W wystąpieniu laureata czuć było nie tylko jego duże wzruszenie, wdzięczność oraz radość, lecz również przemożną nadzieję pisarza, że twórczość literacka w naszym kraju nie da się do końca spauperyzować współczesnym procesom globalizacji oraz komercjalizacji. Spotkanie z poetą zakończył koncert pieśni patriotycznych w wykonaniu białostockiego chóru parafialnego „Mater Ecclesiae".

Uroczysty nastrój towarzyszył poecie również kolejnego dnia jego pobytu w Białymstoku (16 listopada). Uczestniczył on bowiem wtedy w spotkaniu z białostockimi licealistami z IV Liceum Ogólnokształcącego im. Cypriana Kamila Norwida, w trakcie którego opowiadał on między innymi o swojej twórczości oraz o historii i działalności pisma, które od wielu lat redaguje.

Niech symbolicznym podsumowaniem niniejszego sprawozdania będą następujące słowa Krzysztofa Kuczkowskiego z jego tomu Ruchome święta: „Nie wiem, czy to coś znaczy. Prawda nie jest/ ruchoma. Świat krąży wokół prawdy ale prawdy/ znać nie chce. $Z$ samego obracania się nic nie wynika"l.

1 Zob. K. Kuczkowski, Tryb powtarzania, [w:] tegoż, Ruchome święta, Sopot 2017, S. 18. 